\title{
UNA APROXIMACIÓN A LA TEMPORALIDAD ABSOLUTA DEL ARTE RUPESTRE PICTOGRÁFICO DE PUERTO RICO
}

\section{An Approximation to the Absolute Temporality of Pictographic Rock Art in Puerto Rico}

\author{
Reniel Rodríguez Ramos \\ Universidad de Puerto Rico. Recinto de Utuado. \\ Programa de Ciencias Sociales. \\ ORCID: 0000-0003- 2707-6841 \\ Correo-e: reniel.rodriguez@upr.edu \\ Angel A. Acosta-Colón \\ Universidad de Puerto Rico. Recinto de Arecibo. \\ Departamento de Física y Química. \\ ORCID: 0000-0001- 7789-7547 \\ Correo-e: angel.acosta2@upr.edu
}

\author{
Roberto Pérez Reyes \\ Colectivo Much Ma' Ho'l. \\ ORCID: 0000-0002- 9301-8714 \\ Correo-e: robertocamuy00627@hotmail.com
}

Recibido: 1/4/2021 - Aprobado: 24/6/2021

Cómo citar: Rodríguez Ramos, R., Acosta-Colón, A. A., \& Pérez Reyes, R. (2021). Una aproximación a la temporalidad absoluta del arte rupestre pictográfico de Puerto Rico. Ciencia y Sociedad, 46(3), 7-27. Doi: https://doi.org/10.22206/cys.2021.v46i3.pp7-27

\section{Resumen}

Puerto Rico cuenta con un amplio y diverso registro de arte rupestre. Aunque se han realizado importantes contribuciones al estudio de este tipo de manifestación cultural, al presente se tiene información muy limitada sobre su cronología. Sobre la base de 61 fechados obtenidos de los pigmentos orgánicos empleados en la producción de pictografías en diversos contextos arqueológicos de Puerto Rico, se hace una aproximación inicial a la temporalidad absoluta del arte rupestre pintado en la isla. Los resultados obtenidos presentan un panorama amplio del uso de este tipo de manifestación en sus diversos periodos de ocupación, con fechas iniciales directas que se remontan entre cal. 740 y 400 a.C., representando esta la primera evidencia concreta de arte rupestre asociado con los primeros pobladores de la isla. De igual forma, se logró documentar la producción de este tipo de arte rupestre posiblemente asociado a la tradición Saladoide del suroeste de la isla, con fechas entre cal. 220 y 380 d.C. La producción de imágenes pintadas se incrementa en cantidad y diversidad después del 700 d.C., comenzando

\begin{abstract}
Puerto Rico has a very broad and diverse array of rock art. Although some important contributions have been made in the study of this cultural manifestation, currently there is very limited information regarding its chronology. On the basis of 61 radiocarbon dates obtained from organic pigments employed in the production of pictographs in various archaeological contexts from Puerto Rico, an approximation is made about the absolute temporality of painted rock art in the island. The results indicate that this manifestation was registered for an extended period of time, starting between cal. 700-400 BC, when the earliest direct evidence of rock art associated to the first inhabitants of the island is observed. This work also documented rock art likely associated to the Saladoid tradition of southwestern Puerto Rico, with dates between cal. AD 220 and 380. The production of painted images increases in quantity and diversity after $\mathrm{AD} 700$, starting with the representation of anthropomorphic elements, followed by the depiction of zoomorphic pictographs most notably after AD 1000. The depiction of humans and animals,
\end{abstract}


con la grafía de elementos antropomorfos y, posteriormente, de imágenes zoomorfas, las cuales se comienzan a registrar de forma marcada después del 1000 d.C. La producción de pictografías de humanos y animales, así como de otros elementos foráneos, se extiende al periodo colonial de la isla, lo que demuestra continuidades en el uso de las cuevas como contextos de registro tras la llegada de los invasores europeos al territorio de la isla.

Palabras clave: arte rupestre, pictografías, datación por radiocarbono, Puerto Rico.

\section{Introducción}

El Caribe antillano cuenta con un muy diverso y complejo acervo de imágenes plasmadas sobre piedra. Aunque se han realizado importantes avances en el entendimiento de la producción del arte rupestre antillano, todavía restan algunos temas fundamentales por abordarse de manera adecuada. Entre estos, se destaca el establecimiento de cronologías absolutas para este tipo de manifestación cultural en cada una de las islas. Aunque este ha sido reconocido previamente como uno de los aspectos que deben atenderse con mayor premura, todavía nos encontramos en una fase embrionaria en nuestro acercamiento a la temporalidad absoluta del arte rupestre antillano.

Con el fin de aportar algunos datos que puedan proveer un mejor entendimiento del marco temporal y las tendencias diacrónicas registradas en este tipo de manifestación, el presente trabajo presenta los resultados de un programa de fechados radiocarbónicos de pictografías que hemos desarrollado en diversos contextos arqueológicos de Puerto Rico. Cabe destacar que, aunque esta isla es una de las que contiene mayor densidad de contextos rupestres en el Caribe insular, es muy poco lo que se conoce sobre la cronología absoluta de las más de 500 localidades que presentan este tipo de manifestación cultural (Dubelaar et al., 1999; Hayward et al., 2014; Roe, 2009). Sobre la base de los 61 fechados obtenidos hasta el momento, evaluaremos los planteamientos que se han hecho previamente en torno a la cronología del arte rupestre en la isla y presenta- as well as other extraneous elements extends beyond the period of colonization of Puerto Rico, which demonstrates continuities in the use of caves as register contexts after the arrival of the European invaders of the island.

Keywords: rock art, pictographs, radiocarbon dating, Puerto Rico.

remos algunos lineamientos en torno a su desarrollo a través del tiempo.

\section{Acercamientos cronológicos al arte rupestre de Puerto Rico}

Las aproximaciones al tema de la temporalidad de las manifestaciones rupestres en Puerto Rico, al igual que en muchas partes del Caribe antillano, han empleado como criterio principal variantes de métodos de datación relativa como la seriación, análisis estilísticos y de isomorfismos entre medios, entre otros (Dubelaar et al., 1999; Hayward et al., 2014; Rivera Meléndez, 1996). Este último método, propuesto por Roe (1993, 2005; Roe y Meléndez 1995; Roe et al., 1999), emplea el análisis de concomitancias entre las imágenes rupestres y los elementos de diseño encontrados en artefactos obtenidos de contextos arqueológicos con el fin de establecer una estimación cronológica para los diversos tipos de imágenes sobre la base de su presunta asociación.

A nivel contextual, se han propuesto asociaciones cronológicas para las diversas manifestaciones rupestres sobre la base de su proximidad espacial a contextos arqueológicos que han sido datados absolutamente, tanto en espacios cerrados como a cielo abierto. Este es el caso registrado en Maisabel, en el que se estimaron las fechas de las imágenes que se encuentran en una franja de eolianita en la playa Cibuco, en Vega Baja, sobre la base de las dataciones obtenidas en contextos posteriores al 600 d.C. en este yacimiento en asociación a los depósitos de la subserie Elenan Ostionoid identificados (Roe, 1991). De igual forma, 
los petroglifos complejos observados en Caguana han sido datados para, aproximadamente, el 1200 d.C., utilizando como base principal la única fecha obtenida hasta el momento de este tan complejo sitio arqueológico (Alegría, 1983).

Los esquemas crono-culturales de mayor calado en Puerto Rico establecen que, en el marco de las Antillas, las primeras manifestaciones rupestres fueron pictográficas, estando estas limitadas en las Antillas a contextos "Arcaicos" de las islas de Cuba y La Española, así como a Aruba, Bonaire y Curazao al sur del Caribe (Dubelaar, 1986; Dubelaar et al., 1999; Hayward et al., 2009). Se asume además que el arte rupestre "Arcaico" antillano se circunscribía a pictografías geométricas y abstractas. Se piensa también que las sociedades Huecoide y Saladoide que arribaron posteriormente al arco antillano no estuvieron insertadas en la producción de estas manifestaciones rupestres.

En el caso de Puerto Rico, existe un consenso de que los primeros contextos rupestres se registraron después del 600 d.C., en asociación con el desarrollo de lo que ha sido conocido como la serie Ostionoide (sensu, Rouse, 1992). Según lo propuesto por Roe (2005), estas manifestaciones rupestres inician con la producción de imágenes de caras simples entre 600 y 1000 d.C., a las que luego se le añaden proyecciones radiales y tocados entre 1000 y 1200 d.C., eventualmente desarrollándose en las manifestaciones de mayor complejidad estilística registradas en contextos "Taínos" que incluyen figuras a cuerpo completo, caras en forma de corazón y bocas con labios delineados, entre otros elementos. En este modelo se asume una correlación entre desarrollo sociopolítico y la complejidad estilística del arte rupestre de forma marcadamente unilineal, siendo cada una de estas fases asociadas a sistemas de organización social más complejos a través del tiempo, los cuales van desde las tribus completas hasta el desarrollo de los cacicazgos. Cabe destacar que esta idea de un desarrollo unilineal a nivel estructural y superestructural ha sido problematizada por la gran diversidad social y cultural que existió en la isla a través del tiempo y el espacio (Rodríguez Ramos, 2010).

Al presente, en Puerto Rico se han identificado muy pocos ejemplos de arte rupestre posteriores al periodo de contacto. Uno de estos fue registrado en Isla de Mona por Samson et al. (2016), quienes documentaron la presencia de inscripciones de emblemas cristianos, fechas y nombres. Dichos estudios generaron además los primeros fechados absolutos para el arte rupestre en el archipiélago de Puerto Rico, no solo siendo obtenidos directamente de las imágenes, sino también del carbón que se encuentra en la superficie subyacente a estas (Samson et al., 2017). Otro elemento novedoso de este proyecto fue la incorporación de fechados por uranio/torio empleados para establecer las fechas más recientes posibles de dos imágenes cubiertas por espeleotemas, con fechas de $1088 \pm 18$ d.C., $1244 \pm 8$ d.C. y $1703 \pm 4$ d.C. Estas investigaciones también arrojaron información novedosa en la isla sobre los pigmentos empleados, los cuales se realizaron principalmente sobre la base de guano, carbón y ocre. El tema de la composición de los pigmentos es definitivamente un asunto en el que todavía falta mucho por recorrer en los estudios del arte rupestre de Puerto Rico, a diferencia de lo visto en otras islas como Cuba y La Española, en donde se han dado importantes avances (Fernández et al., 2018; Morbán Laucer, 1979; Veloz Maggiolo, 1970).

Aunque los mencionados estudios han aportado elementos significativos para el entendimiento del desarrollo del arte rupestre en la isla, al presente existe muy poca información en torno a la temporalidad absoluta de este tipo de manifestación, lo que limita la resolución cronológica de las interpretaciones hechas hasta el momento. Con el fin de comenzar a crear pautas temporales absolutas para contextualizar el arte rupestre de la isla, desarrollamos un programa de datación de imágenes, cuyos métodos discutimos a continuación. 


\section{Metodología}

Según mencionáramos previamente, en este estudio se ha obtenido un total de 61 fechados de pictografías de Puerto Rico. Con el fin de tener amplitud espacial y temporal en nuestro muestreo, tratamos de obtener fechados de cuevas en diversas partes de la isla, tanto de las formaciones cársicas del norte como del sur (Figuras 1 y 2). De las 11 cuevas muestreadas, las ubicadas al norte incluyen las cuevas
Ventana, Matos y Soto en Arecibo, Catedral en Hatillo, Gemelos y Lagartos en Morovis y El Abono en Utuado. Al sur, se muestrearon las cuevas Lucero y Palomas en Juana Diaz, y La Pita y LJ-22 en Lajas. Además de las dataciones obtenidas en nuestra investigación, se consideran aquí también los resultados de fechados de carbono-14 y de uranio-torio obtenidos por Samson et al. $(2016,2017)$ en las Cuevas 6 y 8 de Isla de Mona.

\section{Figura 1}

\section{Contextos rupestres muestreados en el presente estudio}

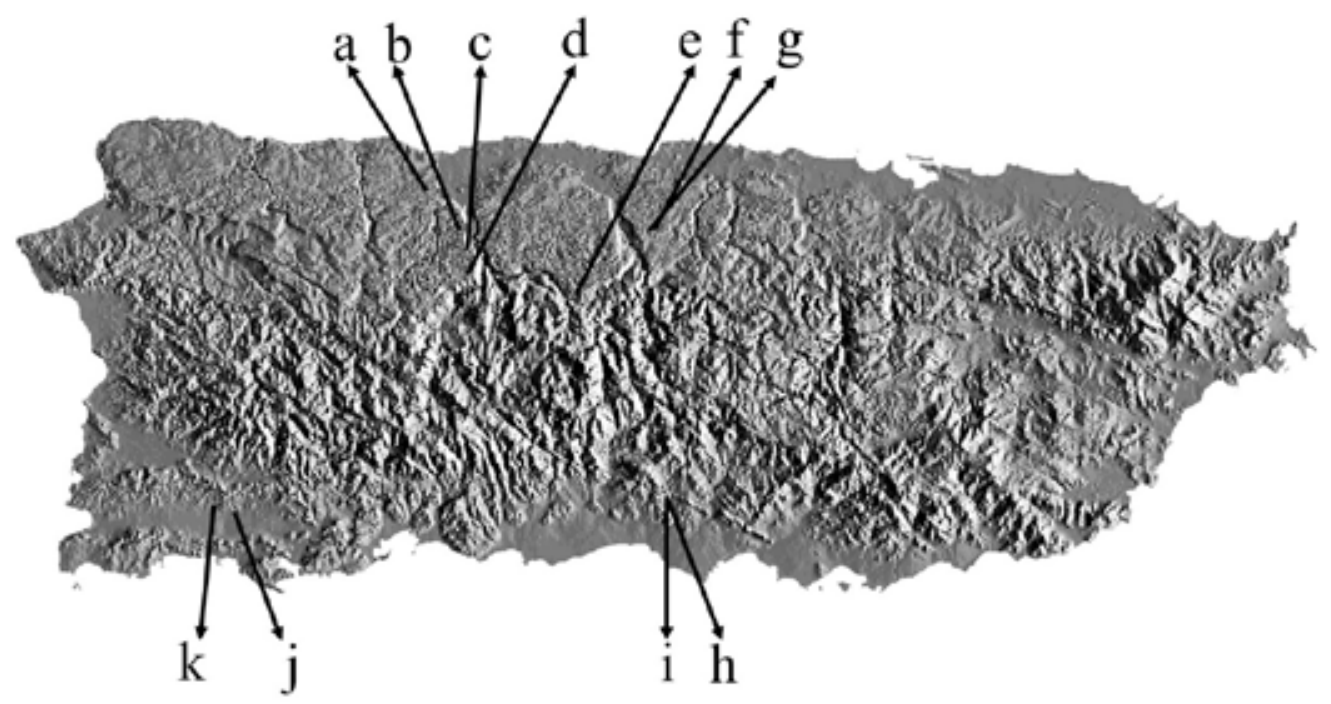

Nota. a: Cueva Catedral; b: Cueva Matos; c: Cueva Ventana Intermedia; d: Cueva Soto; e: Cueva del Abono; f: Cueva Gemelos; g: Cueva Lagartos; h: Cueva Paloma; i: Cueva Gemelos; j: Cueva LJ-22; k: Cueva La Pita.

En la obtención de las muestras de pigmento de las pictografías fechadas, se siguieron los protocolos establecidos por Rowe (2005), según han sido también aplicados de manera exitosa en Isla de Mona por Samson et al. (2017). Con el fin de preservar la integridad morfológica de las imágenes, intentamos ser lo más conservadores posible en la remoción de las muestras para fechado. Las muestras de pigmento obtenidas fueron aproximadamente de 1 a $2 \mathrm{mg}$, siendo extraídas de manera que no borraran ningún elemento específico de la imagen ni alteraran su configuración general. El material fue removido con equipo dental de metal esterilizado, y fue luego ubicado en recipientes de cristal sellados para su eventual procesamiento. Cada pictografía fue fotografiada antes y después de la remoción de la muestra para ubicar con exactitud el área impactada, así como su morfología original y remanente. Las muestras de pigmento para fechado radiocarbónico fueron procesadas con espectrometría de masas con acelerador de partículas por el Dr. Alex Cherkinsky en el Center for Applied Isotope Studies de la Universidad de Georgia. Los resultados de todos estos fechados fueron calibrados utilizando las correcciones más recientes provistas por el programa CALIB 8.10 (Tabla 1; Stuiver et al., 2021). 
Figura 2

Imágenes fechadas en el presente estudio (no a escala)

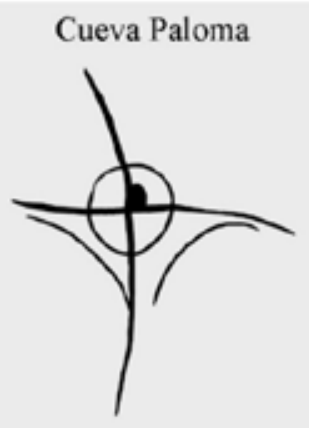

CT-25
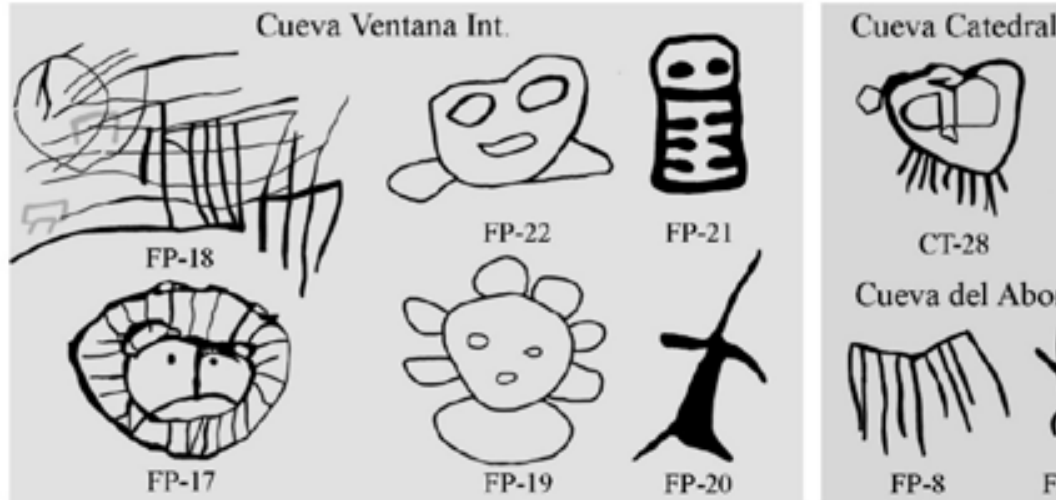

Cueva del Abono

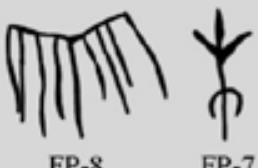

FP-8

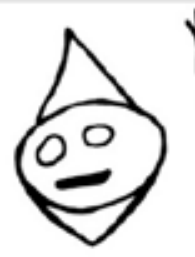

CT-20
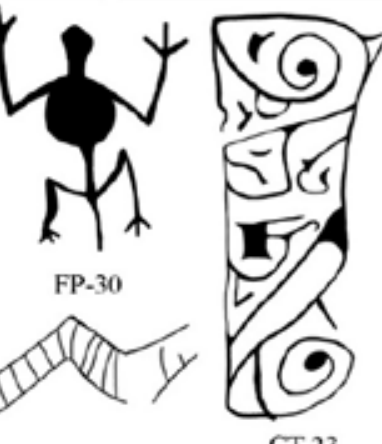

CT-23

FP-34

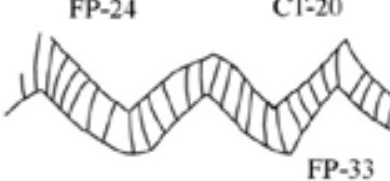

Cueva de los Lagartos

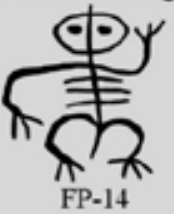

Las Cuevas (LJ-22)

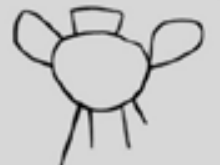

CT-1
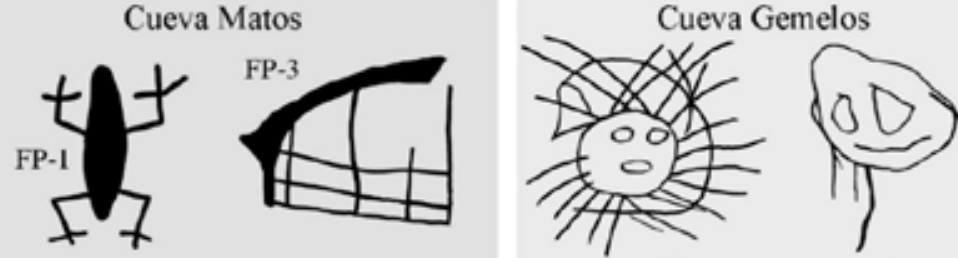

FP-12
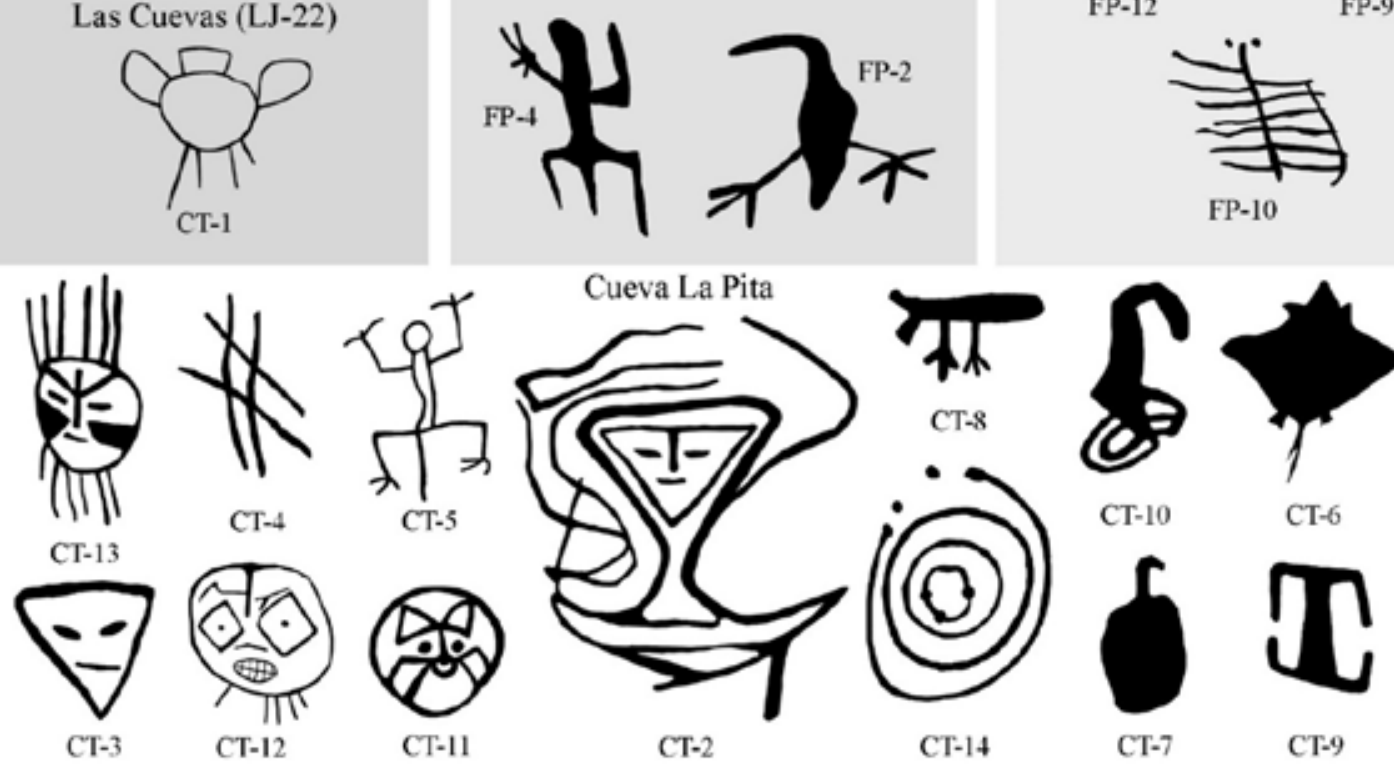

Nota. No se incluyen imágenes de piroglifos y de pictografías que arrojaron fechados modernos o controvertibles. 
En la presente discusión, se presentará el rango calibrado a dos sigmas de cada una de las fechas. Todos los contextos muestreados fueron cartografiados empleando un rastreador LIDAR (Laser Imaging Detection and Ranging) modelo Geoslam Zeb1.

Es de suma importancia destacar que, aunque el uso de los fechados radiocarbónicos ha sido considerado por muchos investigadores como el método de mayor resolución disponible para datar absolutamente los pigmentos orgánicos derivados de pictografías (Gutiérrez Calvache y Arrazcaeta Delgado, 2006), su efectividad ha sido materia de mucho debate, a raíz de los diversos errores que pueden reflejarse en los resultados por distintos factores. Entre los problemas que pueden surgir, se destaca la posibilidad del fechado de pigmentos compuestos total o parcialmente de materia orgánica derivada de un organismo que pereció (por ejemplo, carbón) o la depositó (por ejemplo, guano) mucho antes del acto de pintar la imagen (problema del "carbón viejo"; véase Rowe, 2009). Otro asunto se registra cuando se pintan imágenes con pigmentos creados por la mezcla de componentes orgánicos de distintas temporalidades, o cuando las imágenes son retocadas, introduciendo así pigmentos asincrónicos. Además, se puede registrar contaminación de las muestras de pintura por factores como el crecimiento o la inclusión de bacterias u hongos. Estos elementos, así como otros que han sido planteados (Bednarik 2000; Ruiz y Rowe, 2014), hacen evidente que los resultados de este tipo de procedimiento deben ser tomados con cautela, en especial cuando no existen depósitos arqueológicos asociados que puedan servir para corroborar la temporalidad de estas imágenes.

Los problemas del uso de fechados radiocarbónicos se hicieron palpables particularmente en el caso de lo que hemos denominado como piroglifos, identificados a su vez por Martínez Torres $(2008,2021)$ como "imágenes con tea". Estos son producidos por una técnica análoga al fumage que envuelve "la deposición de los residuos de una llama (hollín) sobre un determinado soporte, quedando adherido éste en la superficie" (Pérez Esteban, 2014, p. 5) con el fin de trazar formas. El grosor de las pictografías, el cual varía entre 3 y $6 \mathrm{~cm}$., y lo difuso de sus márgenes indica el empleo de antorchas (por ejemplo, jachos o teas) con mecha contenida en su producción, como se refleja además por las numerosas marcas ahumadas (como torch marks) que se encuentran en la periferia de algunas de las imágenes. Es muy probable que la resina empleada para algunas de estas antorchas haya sido extraída de maderas como el tabonuco (Dacryodes excelsa) o el almácigo indio (Bursera simaruba), cuyo uso en la producción de arte rupestre fue documentado recientemente en isla de Mona (Samson et al., 2017). Este tipo de imagen ha sido documentada en Cueva Soto, Cueva Ventana Intermedia y Cueva La Pita, siendo además observado en diversos contextos de Isla de Mona (Michael B. Lace, comunicación personal 2019). Debido a las dudas levantadas por la amplitud cronológica observada en imágenes fechadas de un mismo panel, procedimos a datar dos escritos de nombres modernos realizados con este método en Cueva La Pita, uno de los cuales leía Nelson y el otro Alfredo. El hecho de que estas grafías arrojaran fechados sumamente antiguos, de cal. 2140-1940 a.C. y cal. 2910-2880 a.C., respectivamente, hace obvio que no contamos con los métodos necesarios para poder datar este tipo de imagen adecuadamente. Por esta razón, no estaremos incorporando ninguno de los fechados obtenidos de piroglifos de Cueva Soto en la presente discusión. 


\section{Tabla 1}

\section{Fechados de radiocarbono de pictografías muestreadas}

\begin{tabular}{|c|c|c|c|c|c|c|c|c|c|}
\hline Sitio & Ubicación & Muestra & Edad rad. & $2 S L$ & $2 \mathrm{SH}$ & Media $2 \sigma$ & Num. Lab. & $\mathrm{c} 13 / 12$ & Material \\
\hline Cueva Catedral & Hatillo & CT-28 & $380 \pm 35$ & 1450 & 1630 & 1540 & UGAM-46785 & -30.1 & Pigmento orgánico \\
\hline Cueva Catedral & Hatillo & CT-29 & Moderno & & & & UGAM-46786 & & Pigmento orgánico \\
\hline Cueva Catedral & Hatillo & CT-30 & Moderno & & & & UGAM-46787 & & Pigmento orgánico \\
\hline Cueva Lagartos & Morovis & FP-14 & $610 \pm 40$ & 1300 & 1410 & 1355 & UGAM-30029 & -28.5 & Pigmento orgánico \\
\hline Cueva del Abono & Utuado & FP-7 & $320 \pm 30$ & 1490 & 1640 & 1565 & UGAM-30024 & -29.6 & Pigmento orgánico \\
\hline Cueva del Abono & Utuado & FP-8 & $280 \pm 30$ & 1510 & 1670 & 1590 & UGAM-30025 & -31.9 & Pigmento orgánico \\
\hline Cueva Gemelos & Morovis & FP-9 & $1230 \pm 65$ & 660 & 970 & 815 & UGAM-30026 & -25.3 & Pigmento orgánico \\
\hline Cueva Gemelos & Morovis & FP-10 & $410 \pm 40$ & 1430 & 1630 & 1530 & UGAM-30027 & -26.8 & Pigmento orgánico \\
\hline Cueva Gemelos & Morovis & FP-12 & $870 \pm 40$ & 1050 & 1260 & 1155 & UGAM-30028 & -30.1 & Pigmento orgánico \\
\hline Cueva La Pita & Lajas & CT-2 & $1140 \pm 30$ & 780 & 990 & 885 & UGAM-46762 & -30.7 & Pigmento orgánico \\
\hline Cueva La Pita & Lajas & CT-3 & $1770 \pm 35$ & 220 & 380 & 300 & UGAM-46763 & -30.2 & Pigmento orgánico \\
\hline Cueva La Pita & Lajas & CT-4 & $490 \pm 25$ & 1410 & 1450 & 1430 & UGAM-46764 & -27.3 & Pigmento orgánico \\
\hline Cueva La Pita & Lajas & CT-5 & $590 \pm 30$ & 1300 & 1420 & 1360 & UGAM-46765 & -25.9 & Pigmento orgánico \\
\hline Cueva La Pita & Lajas & CT-6 & $970 \pm 20$ & 1020 & 1160 & 1090 & UGAM-46766 & -27.9 & Pigmento orgánico \\
\hline Cueva La Pita & Lajas & CT-7 & $930 \pm 20$ & 1040 & 1160 & 1100 & UGAM-46767 & -28.6 & Pigmento orgánico \\
\hline Cueva La Pita & Lajas & CT-8 & $850 \pm 30$ & 1050 & 1270 & 1160 & UGAM-46768 & -27.2 & Pigmento orgánico \\
\hline Cueva La Pita & Lajas & CT-9 & $600 \pm 20$ & 1310 & 1400 & 1355 & UGAM-46769 & -27.8 & Pigmento orgánico \\
\hline Cueva La Pita & Lajas & CT-10 & $640 \pm 30$ & 1290 & 1400 & 1345 & UGAM-46770 & -27.1 & Pigmento orgánico \\
\hline Cueva La Pita & Lajas & CT-11 & $1060 \pm 30$ & 900 & 1030 & 965 & UGAM-46771 & -29 & Pigmento orgánico \\
\hline Cueva La Pita & Lajas & CT-12 & $920 \pm 25$ & 1030 & 1200 & 1115 & UGAM-46772 & -27.8 & Pigmento orgánico \\
\hline Cueva La Pita & Lajas & CT-13 & $1010 \pm 20$ & 990 & 1120 & 1055 & UGAM-46773 & -26.5 & Pigmento orgánico \\
\hline Cueva La Pita & Lajas & CT-14 & $960 \pm 20$ & 1030 & 1160 & 1095 & UGAM-46774 & -27.2 & Pigmento orgánico \\
\hline Cueva La Pita & Lajas & CT-15 & $3650 \pm 25$ & & & & UGAM-46775 & -32.9 & Hollín \\
\hline Cueva La Pita & Lajas & CT-16 & $4260 \pm 20$ & & & & UGAM-46776 & -29.1 & Hollín \\
\hline Cueva LJ-22 & Lajas & CT-1 & $530 \pm 30$ & 1330 & 1440 & 1385 & UGAM-46761 & -26.3 & Pigmento orgánico \\
\hline Cueva Lucero & Juana Diaz & CT-17 & $180 \pm 20$ & 1660 & 1950 & 1805 & UGAM-46777 & -28 & Pigmento orgánico \\
\hline Cueva Lucero & Juana Diaz & CT-20 & $500 \pm 20$ & 1410 & 1440 & 1425 & UGAM-46779 & -28.9 & Pigmento orgánico \\
\hline Cueva Lucero & Juana Diaz & CT-22 & $4070 \pm 40$ & & & & UGAM-46780 & -28.5 & Pigmento orgánico \\
\hline Cueva Lucero & Juana Diaz & CT-23 & $490 \pm 20$ & 1410 & 1440 & 1425 & UGAM-46781 & -30.9 & Pigmento orgánico \\
\hline Cueva Lucero & Juana Diaz & CT-24 & $190 \pm 30$ & 1650 & 1950 & 1800 & UGAM-46782 & -29.6 & Pigmento orgánico \\
\hline Cueva Lucero & Juana Díaz & CT-22b & $3470 \pm 110$ & & & & UGAM-31627 & -27.6 & Pigmento orgánico \\
\hline Cueva Lucero & Juana Díaz & $\mathrm{FP}-24$ & $630 \pm 20$ & 1300 & 1400 & 1350 & UGM-30039 & -27.7 & Pigmento orgánico \\
\hline Cueva Lucero & Juana Díaz & FP-25 & $220 \pm 30$ & 1640 & 1950 & 1795 & UGM-30040 & -26.6 & Pigmento orgánico \\
\hline Cueva Lucero & Juana Díaz & FP-26 & $110 \pm 30$ & 1680 & 1940 & 1810 & UGM-30041 & -29.8 & Pigmento orgánico \\
\hline Cueva Lucero & Juana Díaz & FP-27 & $3140 \pm 40$ & & & & UGM-30042 & -27.1 & Pigmento orgánico \\
\hline Cueva Lucero & Juana Díaz & FP-28 & $630 \pm 50$ & 1280 & 1410 & 1345 & UGM-30043 & -28.7 & Pigmento orgánico \\
\hline Cueva Lucero & Juana Díaz & $\mathrm{FP}-30$ & $730 \pm 35$ & 1230 & 1380 & 1305 & UGM-30045 & -28.7 & Pigmento orgánico \\
\hline Cueva Lucero & Juana Díaz & FP-31 & Moderno & & & & UGM-30046 & & Pigmento orgánico \\
\hline Cueva Lucero & Juana Díaz & FP-32 & Moderno & & & & UGM-30047 & & Pigmento orgánico \\
\hline Cueva Lucero & Juana Díaz & FP-33 & $310 \pm 35$ & 1490 & 1650 & 1570 & UGM-30048 & -29.8 & Pigmento orgánico \\
\hline
\end{tabular}


Reniel Rodríguez Ramos, Angel A. Acosta-Colón y Roberto Pérez Reyes

\begin{tabular}{|c|c|c|c|c|c|c|c|c|c|}
\hline Sitio & Ubicación & Muestra & Edad rad. & $2 \mathrm{SL}$ & $2 \mathrm{SH}$ & Media $2 \sigma$ & Num. Lab. & c13/12 & Material \\
\hline Cueva Lucero & Juana Díaz & FP-34 & $400 \pm 35$ & 1440 & 1630 & 1535 & UGM-30049 & -29.4 & Pigmento orgánico \\
\hline Cueva Lucero & Juana Díaz & FP-35 & $380 \pm 30$ & 1450 & 1630 & 1540 & UGM-30050 & -28.1 & Pigmento orgánico \\
\hline Cueva Matos & Arecibo & FP-1 & $410 \pm 25$ & 1440 & 1620 & 1530 & UGM-30018 & -31 & Pigmento orgánico \\
\hline Cueva Matos & Arecibo & FP-2 & $640 \pm 45$ & 1280 & 1400 & 1340 & UGM-30019 & -28.3 & Pigmento orgánico \\
\hline Cueva Matos & Arecibo & $\mathrm{FP}-3$ & $330 \pm 30$ & 1480 & 1640 & 1560 & UGM-30020 & -31.8 & Pigmento orgánico \\
\hline Cueva Matos & Arecibo & FP-4 & $580 \pm 40$ & 1290 & 1440 & 1365 & UGM-30021 & -28.2 & Pigmento orgánico \\
\hline Cueva Paloma & Juana Diaz & CT-25 & $780 \pm 25$ & 1220 & 1280 & 1250 & UGAM-46783 & -31.3 & Pigmento orgánico \\
\hline Cueva Soto & Arecibo & CT-31 & $3720 \pm 110$ & & & & UGAM-46788 & -25.6 & Hollín \\
\hline Cueva Soto & Arecibo & FP-16 & $2910 \pm 50$ & & & & UGAM-30031 & -26.1 & Hollín \\
\hline Cueva Soto & Arecibo & FP-168 & $2510 \pm 60$ & & & & UGAM-31626 & -30.1 & Hollín \\
\hline Cueva Soto & Arecibo & FP-41 & $4210 \pm 130$ & & & & UGAM-32721 & -30.6 & Hollín \\
\hline Cueva Soto & Arecibo & FP-5 & $480 \pm 30$ & & & & UGM-30022 & -34.5 & Hollín \\
\hline Cueva Soto & Arecibo & FP-6 & $1030 \pm 20$ & & & & UGM-30023 & -31.3 & Hollín \\
\hline Cueva Soto & Arecibo & FP-15 & Moderno & & & & UGM-30030 & & Hollín \\
\hline Cueva Ventana Int. & Arecibo & FP-17 & $300 \pm 20$ & 1510 & 1650 & 1580 & UGM-30032 & -26.4 & Pigmento orgánico \\
\hline Cueva Ventana Int. & Arecibo & FP-18 & $2390 \pm 35$ & -740 & -400 & -570 & UGM-30033 & -29.5 & Pigmento orgánico \\
\hline Cueva Ventana Int. & Arecibo & FP-19 & $1050 \pm 30$ & 900 & 1030 & 965 & UGM-30034 & -29.1 & Pigmento orgánico \\
\hline Cueva Ventana Int. & Arecibo & FP-20 & $400 \pm 30$ & 1440 & 1620 & 1530 & UGM-30035 & -26.6 & Pigmento orgánico \\
\hline Cueva Ventana Int. & Arecibo & FP-21 & $1050 \pm 80$ & 900 & 1030 & 965 & UGM-30036 & -25.5 & Pigmento orgánico \\
\hline Cueva Ventana Int. & Arecibo & FP-22 & $690 \pm 30$ & 1270 & 1390 & 1330 & UGM-30037 & -27.5 & Pigmento orgánico \\
\hline Cueva Ventana Int. & Arecibo & FP-23 & $190 \pm 30$ & 1650 & 1950 & 1800 & UGM-30038 & 28.1 & Pigmento orgánico \\
\hline
\end{tabular}

Otro problema identificado en el fechado de pictografías en este estudio surgió con dos imágenes antropomorfas de Cueva Lucero, las cuales arrojaron fechados sumamente antiguos, de entre cal. 2860-2470 y cal. 1500-1300 a.C. Ambas imágenes son representaciones de caras humanas con proyecciones circulares, o rodillos, en su cabeza y segmentación a nivel facial que puede representar ya sea algún tipo de diseño corporal o la delimitación de los pliegues faciales. Fotos provistas por el arqueólogo Juan González tras realizar nuestro muestreo de dichas imágenes, tomadas en la década de 1970, indican que ambas de estas pictografías fueron retocadas, algo que fue confirmado mediante un análisis computadorizado de los trazos que demostró que las fechas fueron obtenidas de áreas que habían sido retrabajadas. Esto demuestra nuevamente algunos de los problemas en los que se puede incurrir en la toma de muestras para el fechado de estas imágenes, algunas de la cuales pudieron haber sido retocadas con pigmentos que distan mucho del periodo en el que fueron producidas originalmente.
Habiendo establecido estas salvedades, consideramos que gran parte de los fechados contienen importantes marcadores de coherencia intra-contextual que ilustran la empleabilidad de este método para la datación de imágenes realizadas con pigmentos orgánicos. Por ejemplo, en Cueva La Pita tuvimos la oportunidad de fechar diversas pictografías de una misma estación, con resultados sumamente consistentes (Figura 3; Tabla 1). Además, en Cueva Ventana Intermedia evaluamos la secuenciación picto-estratigráfica con dos imágenes pintadas superpuestas, la cual arrojó resultados a nivel absoluto que corresponden con la estratificación observada en la producción de las imágenes (Rodríguez Ramos, 2017). Tomando en cuenta las consideraciones antes expuestas, entendemos que los fechados generados en el presente trabajo tienen una resolución adecuada para proponer algunos lineamientos iniciales para establecer la temporalidad de la producción de pictografías en la isla, los que han de ser sometidos a revisión en estudios posteriores. 
Figura 3

Paneles de Cueva La Pita
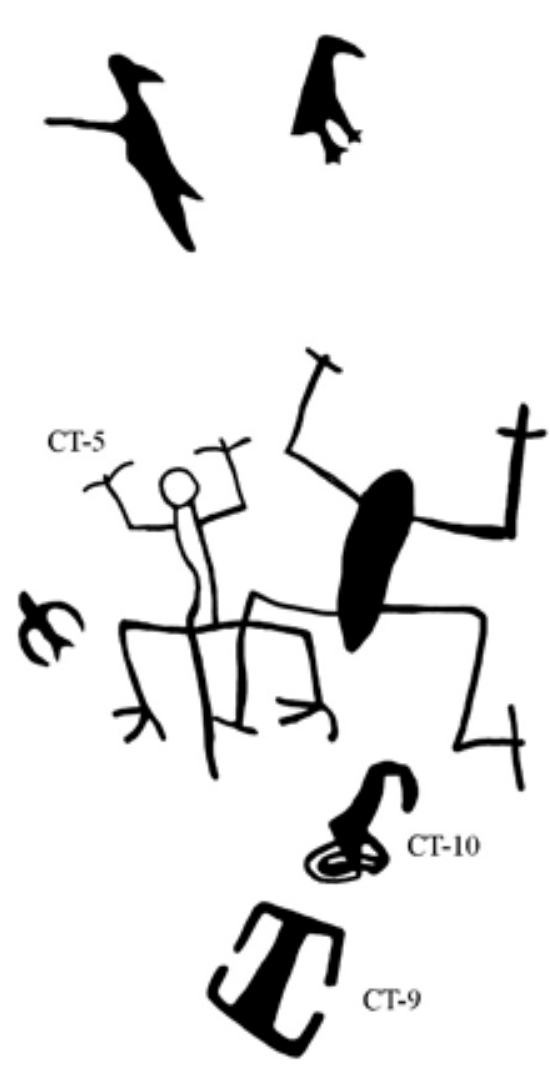
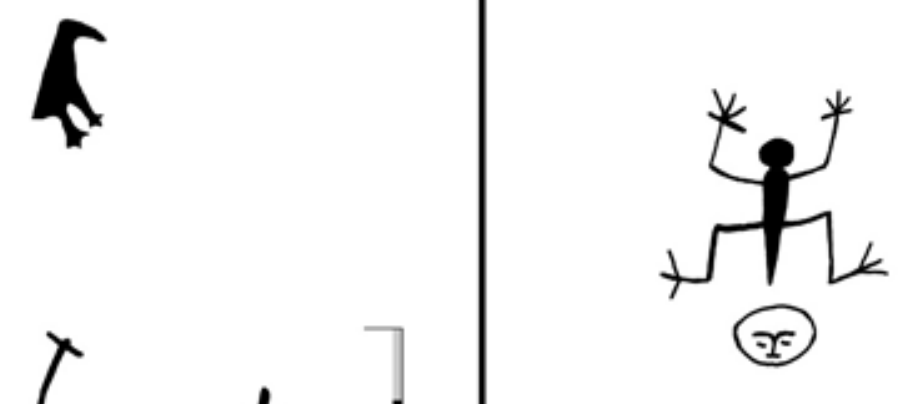
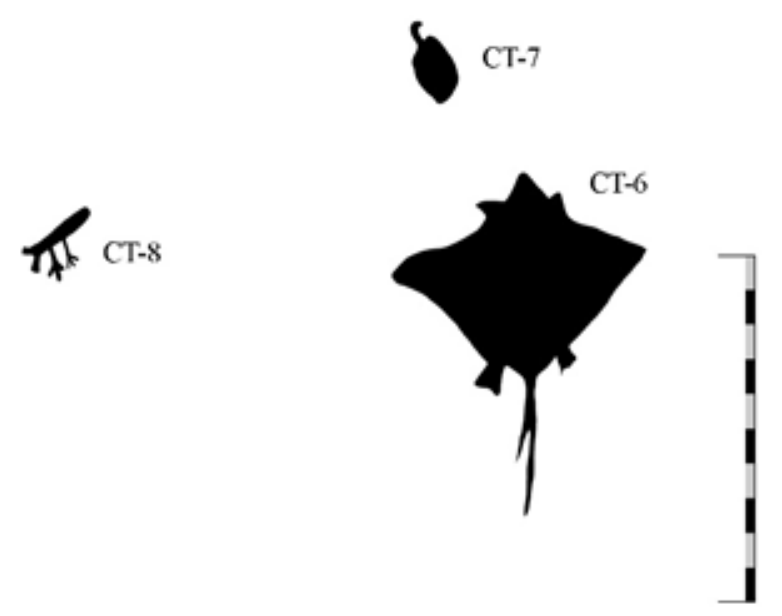

Nota. Ilustrando imágenes fechadas dentro de cada uno de estos (escala de $1 \mathrm{~m}$ ).

\section{Resultados}

Los resultados obtenidos en este estudio reflejan ciertos patrones interesantes en la producción de pictografías en la isla. La fecha de mayor antigüedad viene de un diseño reticulado observado en la Cueva Ventana Intermedia (FP-18), la cual se remonta a cal. 740-400 a.C. Esta pictografía se encuentra en una de las cuatro cuevas superpuestas ubicadas en el Cañón del Río Grande de Arecibo, tres de las cuales presentan estaciones rupestres. En el extremo oeste de Cueva Ventana Superior se encontró uno de los contextos más tempranos asociado a los primeros pobladores de la isla, con un rango de fechados que

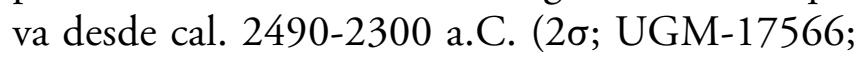

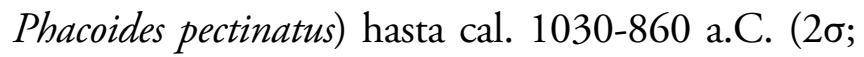
UGM-17564; Neritina sp.) (Rodríguez Ramos et al.,
2019). Aunque la fecha de esta imagen es un tanto más tardía que el contexto más reciente documentado en la Cueva Ventana Superior, es muy probable que se encuentre asociada a los primeros pobladores de la isla, ya que concuerda con el presunto uso de este tipo de diseño abstracto durante este periodo temprano. Este tipo de imagen geométrica ha sido documentado de formas variadas en otros contextos de Puerto Rico, La Española y Cuba.

Cabe destacar que, aunque este es el fechado más antiguo de arte rupestre pictográfico en la isla documentado hasta el momento, en varias cuevas hemos identificado petroglifos en espacios próximos a depósitos con material producido por los primeros pobladores del archipiélago de Puerto Rico, como son los casos de Cueva del Abono, Cueva Matos, 
Cueva Tembladera, Cueva Ventana Superior y Cueva de las Caritas, esta última ubicada en Isla de Mona. Aunque el establecimiento de una cronología para estas imágenes sobre la base de su presunta asociación con dichos depósitos debe ser tomado con cautela, entendemos que se tiene que abordar la posibilidad de que, en efecto, algunos de estos grabados rupestres estén asociados a estos contextos tempranos. El tipo de imagen más común identificado en estas localidades es lo que hemos denominado la cara segmentada, que consiste en rostros antropomorfos con delineamiento parcial o irregular y, en algunos casos, líneas proyectándose desde la cabeza o desde sus ojos a manera de lágrimas (Martínez Torres, 2008; Rodríguez Ramos, 2017). También es común encontrar caras redondas simples como es, por ejemplo, el caso observado en Cueva del Abono. Esperamos que, en un futuro cercano, métodos como la liquenometría y los estudios de microerosión, entre otros (Bednarik, 1992; Benedict, 2009), presenten la resolución necesaria para comenzar a fechar absolutamente este tipo de arte rupestre tallado, que es por mucho el más común en la isla.

Es interesante que de Cueva La Pita obtuvimos el primer fechado en una cueva de la isla que cae dentro de lo que habíamos identificado como un periodo caracterizado por un hiato cronológico en la presencia humana directa del uso de este tipo de espacio el cual, según los fechados disponibles, se extendía entre 200 d.C. y 700 d.C. (Rodríguez Ramos, 2017). La fecha, que se remonta a cal. 220-380 d.C., corresponde a una pictografía de una cara de morfología triangular (CT-3) que se encuentra aledaña a otra similar en tamaño y técnica de ejecución. Ambas fueron producidas por trazos con carbón y son relativamente pequeñas, con un largo promedio de 12 $\mathrm{cm}$. Estas imágenes tienen similitud con algunos de los adornos identificados en la cerámica Saladoide de la isla, en particular por la forma lenticular de sus ojos y el diseño triangular de su contorno facial, por lo que es probable que estas pictografías hayan sido ejecutadas por personas asociadas a esta tradición cultural. Aunque al momento no se ha documentado absolutamente ningún otro contexto rupestre asociado con esta manifestación cultural, en Cueva La Mora, ubicada en el Municipio de Comerio, se ha establecido una posible asociación por el uso de pigmento blanco en la producción de las pictografías que es similar al empleado para la pintura de la cerámica más temprana de esta serie, conocida como el estilo Hacienda Grande.

Cabe señalar que, al presente, no contamos con ninguna evidencia de la producción de pictografías ni de presencia humana en cuevas entre cal. $400 \mathrm{y}$ 700 d.C. (Figura 4). Aunque esto puede ser producto del muestreo, también hay que considerar la posibilidad de que se hubiesen realizado actividades en las cuevas que no dejaron una huella material que hayamos podido documentar hasta el presente, o que en efecto existiese algún tipo de restricción en el uso de este tipo de espacio durante este periodo. Cabe también la posibilidad de que algunos de los petroglifos presentes en estos espacios fechen para este periodo, pero, como mencionáramos previamente, al momento no contamos con evidencia cronológica directa para datar la producción de este tipo de grabado pictórico en la isla.

La producción de arte rupestre pictográfico se comienza a registrar nuevamente después del 700 d.C. La primera evidencia viene de una imagen antropomorfa, con trazos burdos documentada en Cueva Gemelos (FP-9), con fecha de cal. 660-970 d.C. La irregularidad de los trazos da la impresión de una falta de dominio de la técnica pictográfica. Un elemento interesante de esta imagen es el uso de proyecciones que han sido comúnmente descritas como "barbas" en el arte rupestre de la isla. La fecha obtenida coincide con el rango temporal establecido por Roe (2005) para este tipo de diseño.

La próxima imagen de mayor antigüedad se documentó en Cueva La Pita (CT-2), con fechas entre cal. 780 y 990 d.C. Esta consiste en una cara triangular encapsulada por trazos curvilíneos, la cual 
representa un diseño muy atípico en la iconografía documentada hasta el presente en Puerto Rico. La precisión del trazo y la configuración facial muestran marcadas similitudes a la de las pictografías de caras triangulares de esta cueva descritas previamente, lo que puede estar indicando una continuidad en dicha tradición pictórica hasta este periodo. De hecho, esta continuidad coincide con la que se ha visto en las tradiciones de la cerámica Saladoide de la isla, las cuales se extienden por varios siglos después de lo propuesto en el esquema de Rouse (1992) (véase Pestle et al., 2013; Rodríguez Ramos, 2010).

\section{Figura 4}

Fechados radiocarbónicos de depósitos arqueológicos y pictografias en cuevas de Puerto Rico (calibrados a dos sigmas)

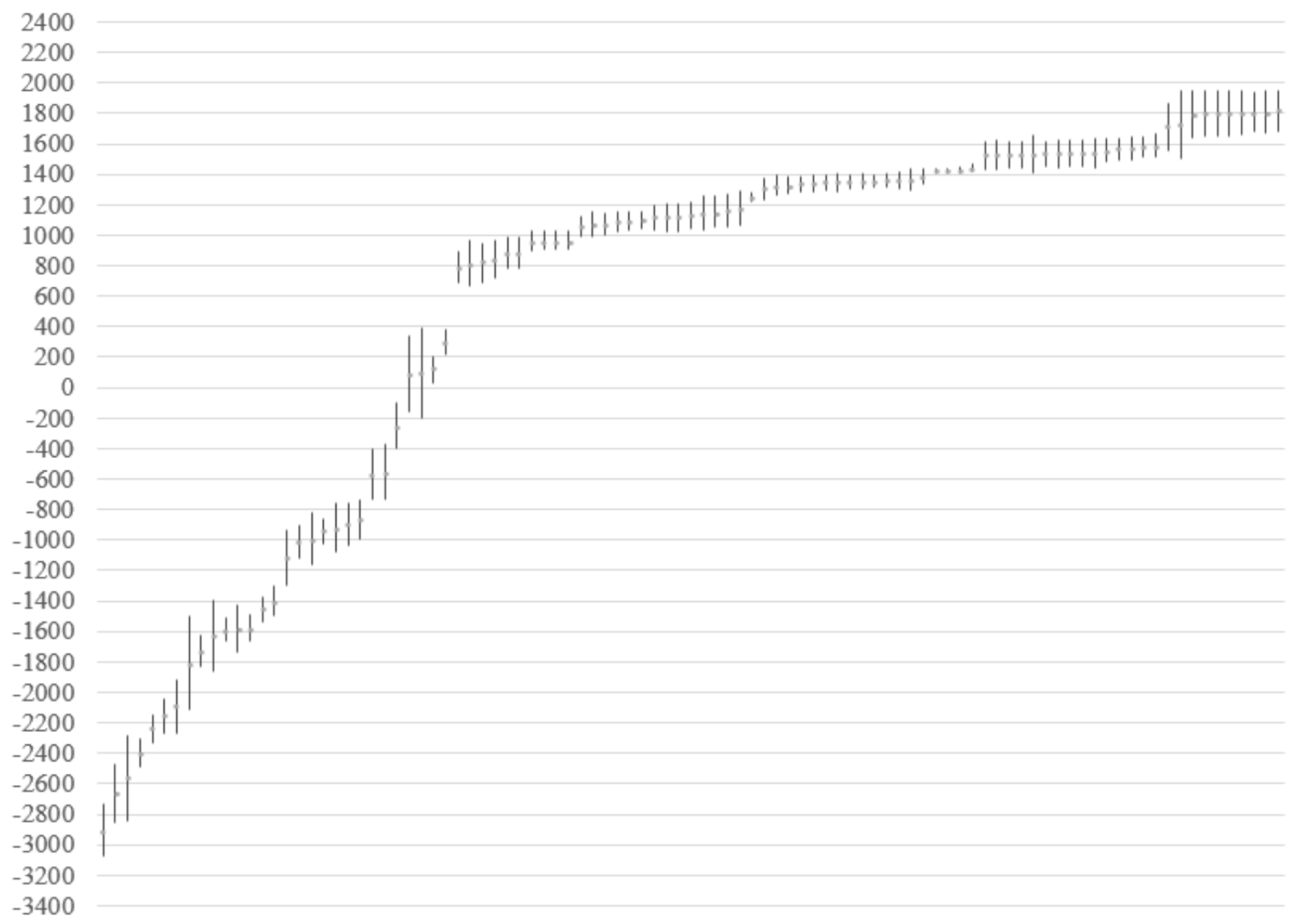

A partir del 900 d.C. se nota un marcado incremento en la cantidad y diversidad de imágenes pintadas, en algunos casos siendo plasmadas en paneles que contienen diversos tipos de figuras producidas concomitantemente. Entre las imágenes que hacen su aparición se encuentra el diseño conocido el "bebé en frazada" (Frasetto, 1960), "nińo enfajado" (López Belando, 2018) o los "ancestros envueltos" (Roe, 2009). Este tipo de imagen se documentó en
Cueva Ventana Intermedia (FP-21), con una fecha de cal. 900 a 1030 d.C. Esta pictografía parece haber sido producida con una cota de algodón impregnada en pigmento, como se puede apreciar por el grosor de los trazos y su frontera porosa con la superficie rocosa. En la misma estación donde se identificó esta imagen, y para exactamente la misma fecha, se documentó lo que ha sido de manera común caracterizado como un diseño solar, que consiste en una 
cara redonda bordeada por proyecciones semicirculares (FP-19). Esta imagen se encuentra en un panel que contiene otros dos diseños solares asociados, los cuales en conjunto pueden estar representando algún tipo de elemento representativo del orden celeste. Este tipo de diseño solar corresponde iconográficamente con otros representados en petroglifos, según está documentado en el Mural de Zama en Jayuya, la Cueva Chito en Isla de Mona y en la Playa Los Tubos en Manatí (Rodríguez Ramos, 2017).

Estos diseños son coetáneos con una pictografía documentada en Cueva La Pita (CT-11), que presenta una cara con un diseńo de lazo sobre los ojos y proyecciones del pliego de la boca hacia sus lados con una fecha de cal. 900-1030 d.C. Dichos elementos, adicionados al espacio facial, podrían reflejar los diseños producidos en la pintura corporal durante este periodo. Empero, también se puede explorar la posibilidad de que el diseño que se ve sobre los ojos represente orejas puntiagudas, las cuales, en combinación con las marcas que se proyectan desde la boca que delimitan lo que aparenta ser un hocico, podrían servir como motivos figurativos de algún tipo de felino esquematizado. Uno de los felinos que jugó un rol importante para las sociedades indígenas de la zona lo fue el jaguar. Aunque este tipo de animal no es parte de la fauna antillana, se ha establecido su presencia iconográfica en lugares como la cueva de Hoyo de Sanabe y la Línea del Ferrocarril en República Dominicana (López Belando, 2018), mientras que en Puerto Rico se han encontrado colmillos de jaguar en asociación a contextos Huecoide y Saladoide (Chanlatte y Narganes, 2005 Laffoon et al., 2014), así como réplicas de colmillos de jaguar hechas en hueso y concha. También se han identificado vasijas con dientes desplegados y lenguas proyectándose desde la boca, así como un punteado blanco que ha sido asociado a la representación de este tipo de animal en el área Istmo-Colombiana (Fernández Esquivel et al., 2012; Rodríguez Ramos y Hoopes, en imprenta). La importancia mítica de este animal era tal que se ha establecido incluso que, ante su ausencia física, fue sustituido míticamente por el perro en las Antillas (Rodríguez López, 2001). Entendemos que estos elementos abren la puerta a la posibilidad de que esta pictografía pueda estar asociada a la representación de este felino o, al menos, esta categoría de animal.

La producción de imágenes presenta importantes cambios a partir de 1000 d.C., cuando se comienza a registrar el uso de pintura en positivo, que consiste en el relleno total o parcial de las pictografías con pigmentos. Esto se puede apreciar en una imagen antropomorfa documentada en Cueva La Pita (CT-13), con fechas de cal. 990-1120 d.C. Esta pictografía presenta lo que parecen ser diseños faciales en ambos lados de la cara, con proyecciones lineales sobre y debajo del contorno de la imagen. Esta clase de diseńo puede marcar algún tipo de emblema de identidad para el ser o el ente que está siendo representado. Esta imagen se encuentra asociada en el mismo panel a un diseño de círculos concéntricos con un punteado marginal (CT-14), con una fecha de cal. 1030-1160 d.C. En esta cueva este es el panel que se encuentra en la parte más al interior, en un área de difícil acceso y muy poca iluminación.

Después del 1100 d.C., se comienza a notar una presencia mucho más marcada de pictografías zoomorfas, representando principalmente organismos marinos y aves de forma naturalista. Esto se refleja en un panel pictográfico en Cueva La Pita, en el que se muestra una mantarraya en asociación temporal y espacial con varias aves (Figura 2). La imagen de la mantarraya es la de mayor tamaño documentada en el presente estudio, midiendo $1.1 \mathrm{~m}$ de largo. Las tres pictografías fechadas de este panel muestran una clara contemporaneidad, con fechas de cal. 10201160 d.C. para la mantarraya (CT-6), cal. 1040-1160 para uno de los pájaros (CT-7) y cal. 1050-1270 d.C. para la otra representación ornitomorfa (CT-8). Este énfasis en la producción de imágenes zoomorfas después del 1100 d.C. puede representar la incorporación de nuevas subjetividades en la articulación del mundo espiritual de las sociedades de la isla, en las que algunos de estos animales pudieron haber 
asumido roles importantes en las narrativas superestructurales. La incorporación de las representaciones de animales en el arte rupestre puede también tener que ver con los cambios estructurales que se observan en la isla para este momento, según se refleja por el incremento en la cantidad de bateyes y la producción de artefactos suntuarios de despliegue público como los aros líticos, codos de piedra y cemíes elaborados, entre otros elementos asociados a la reserva simbólica que hemos denominado "Tainidad” (Oliver, 2009; Rodríguez Ramos, 2010).

Mientras al sur de la isla se nota un incremento en la producción de imágenes zoomorfas con pintura en positivo, al norte se ve en contextos contemporáneos la continuidad en la producción de diseños solares, como se aprecia en la imagen documentada en Cueva Gemelos (FP-12), con fechas de cal. 10501260 d.C. Este tipo de diseño solar tiene marcadas similitudes con imágenes registradas, no solo en Puerto Rico, sino también en Cuba y La Espańola. Cabe destacar que, para este tiempo, se habían establecido importantes esferas de intercambio dentro de las cuales se estaban tramitando distintos tipos de materiales entre los habitantes de las islas, entre los que se destaca el jade (Rodríguez Ramos, 2011). Entendemos que, además de estos tipos de materiales, el bien principal tramitado en estas redes de interacción era la información (Mol, 2014). Es por esta razón que la producción de imágenes con una configuración estructural similar en las diversas islas pudo haber sido el producto del trueque de la información y las narrativas que pudieron haber estado atadas a estas imágenes.

\section{Figura 5}

Distribución cronológica de imágenes fechadas

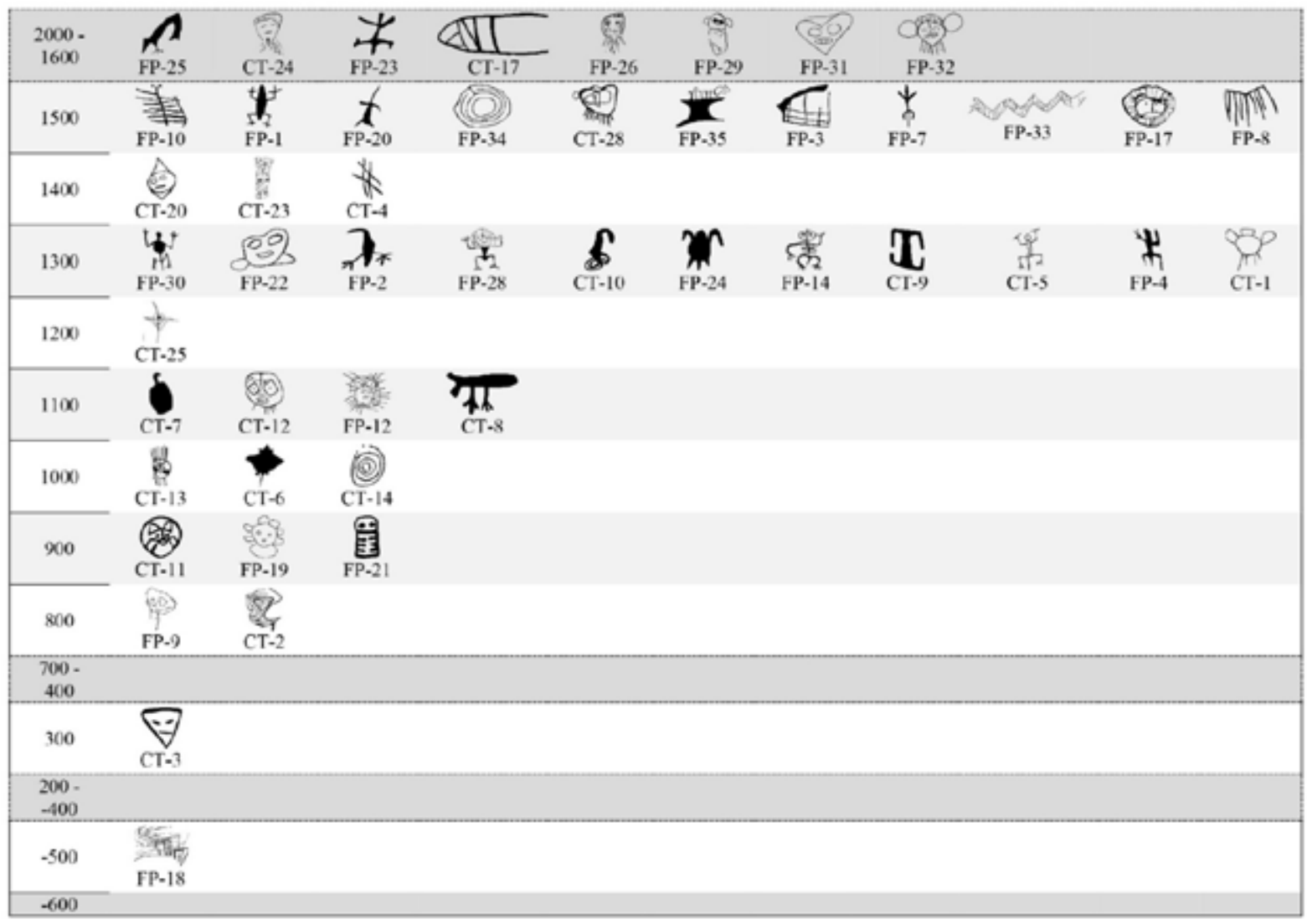

Nota. No a escala. Para su ubicación, se considera la media de la distribución a dos sigma de los fechados calibrados. 
Las muestras disponibles nos indican que la producción de pictografías registró un incremento importante después del 1300 d.C., cuando se comienza a ver la representación de escenas como ha sido documentado, por ejemplo, en las cuevas de Borbón de la República Dominicana (López Belando, 2018). Esto se puede apreciar en uno de los paneles de Cueva La Pita, en el que se registran dos figuras de reptiles con los pies entrelazados, una de las cuales se hizo con trazos dejando el centro al vacío, mientras que la otra se hace con pintura en positivo, creando así un sentido de dualidad. La imagen realizada con trazos lineales (CT-5) fechó para cal. 1300-1420 d.C. La producción de imágenes compuestas también se ve reflejada en Cueva Lagartos en Morovis, en la que pudimos fechar una de tres pictografías antropomorfas que fueron producidas con los mismos cánones artísticos, que incluyen brazos curveados y cabezas elipsoidales bifurcadas con un ojo a cada lado de la línea divisoria. La fecha para una de las imágenes antropomorfas de esta escena (FP-14) fue de cal. 1300-1410 d.C.

Para este tiempo se continúan produciendo imágenes zoomorfas, con una mayor representación de elementos marinos en la parte sur de la isla. Esto se refleja en Cueva Lucero por la producción de dos tortugas idénticas en ejecución y tamaño, una de las cuales (FP-24) fechó para cal. 1300-1420 d.C. Estas son muy parecidas a las clasificadas dentro de la Escuela de Borbón por López Belando (2018), registradas tanto en La Española como en Jamaica. De igual forma, se documentó una pictografía zoomorfa en Cueva La Pita (CT-10), con una fecha de cal. 1290-1400 d.C. Esta imagen se encuentra en un panel (figura 2) en asociación con otro elemento zoomorfo no identificado (CT-9) que fechó para cal. 1310-1400 d.C., estando a su vez relacionadas con la imagen de lo que aparenta ser un reptil descrita (CT-5) previamente, la cual, según habíamos establecido, fechó para cal. 1300-1420 d.C.

Para este momento se nota un incremento en la producción de imágenes de reptiles, siendo algunos de estos esquematizados con trazos lineales, como se observa en Cueva Matos (FP-4) con una fecha de cal. 1290-1440 d.C. Otros, por su parte, son realizados con pintura en positivo, como se puede observar en Cueva La Pita, según fue mencionado previamente. Algunos de estos reptiles comienzan a presentar elementos ańadidos, entre los que se destaca un círculo en la zona torácica. Esto se puede apreciar claramente en una imagen de Cueva Lucero (FP-30), con fechas de cal. 1230-1380 d.C. Cabe destacar la relación que aparenta reflejarse entre este tipo de imagen de reptil estilizado con las de figuras humanas a cuerpo completo con manos y pies desplegados, como la que se observa en Cueva Lucero (FP-28), con fecha de cal. 1280-1410 d.C. Esta figura se caracteriza por su tocado decorado y una cabeza en forma de corazón, la cual se sobrepone a un cuerpo esquematizado de forma minimalista. Nos parece que esta relación observada en la representación de seres humanos y reptiles debe ser abordada con más detalle en estudios futuros, porque puede estar denotando algún otro tipo de interacción simbólica entre ambos tipos de organismos dentro de los formatos de diseño articulados durante este tiempo.

Interesantemente, la mencionada imagen antropomorfa de manos y pies desplegados de Cueva Lucero muestra un claro paralelismo iconográfico con petroglifos registrados en otros contextos como los bateyes, las cuevas, los ríos y las rocas en las orillas de la playa. Esto no solo se refleja en la imagen antropomorfa previamente descrita, sino también en una cara en forma de corazón ubicada en Cueva Ventana Intermedia (FP-22), que fechó para cal. 1270-1390 d.C. Es interesante que ambas de estas imágenes muestran similitudes marcadas con las observadas en los petroglifos 8 y 9 de la plaza A de Caguana, sitio del que la única fecha corresponde con el rango temporal de ambas de estas imágenes, siendo de cal. 1210-1420 (2б; Y-1244; madera; Alegría 1983).

Un dato interesante recogido en esta investigación es la marcada representación de imágenes producidas durante el periodo precolonial tardío y el colonial temprano, como también fue registrado 
en los fechados obtenidos por Samson et al. (2017) en Isla de Mona. Muchas de las imágenes documentadas corresponden con los elementos iconográficos presentes en contextos previos a la invasión europea, incluyendo diseños antropomorfos realizados con trazos de carbón, imágenes con pintura en positivo y algunos elementos abstractos. Interesantemente, para este tiempo tenemos la primera evidencia directa de la creación de un palimpsesto producido por imágenes superpuestas, registrado en Cueva Ventana Intermedia, en donde una representación zoomorfa con sus extremidades desplegadas (FP-20), datada para cal. 1440-1620 d.C., se hizo sobre uno el diseño solar descrito anteriormente en esta cueva (FP-19) que fechó para cal. 900-1030 d.C. Previo a esta fecha no se había documentado ninguna instancia de superposición de pinturas en ninguno de los contextos estudiados.

Algunas de las pictografías realizadas durante este periodo fueron documentadas en una de las cuevas ubicadas más al interior de la isla, la Cueva del Abono, lo que confirma que algunos grupos estaban fuera de las localidades que eran foco de colonización durante este periodo temprano (véase Castanha, 2011). En esta cueva se fecharon dos pictografías identificadas en una estación ubicada cerca de su entrada principal, una de las cuales corresponde con el motivo de los consabidos "lagartijos" (FP-7) fechada para cal. 1490-1640 d.C. Como se estableciera previamente, este tipo de imagen comienza a ser producido en tiempos precolombinos tardíos y, según los datos generados en el presente estudio, se mantiene vigente como elemento iconográfico hasta después del periodo de contacto. La segunda imagen es más difícil de asociar con alguna silueta en particular, siendo un conjunto de líneas paralelas proyectándose hacia abajo desde una línea horizontal (FP-8), con fecha de cal. 1510-1670 d.C. Las fechas que tenemos hasta el momento indican claramente que estas imágenes no guardan relación cronológica con el contexto arqueológico identificado al otro extremo de esta cueva, el cual fue fechado para cal. 3080-2730 a.C. (2б; UGM-30015; Strombus sp.; Rodríguez Ramos, 2017).
Una de las estaciones que presenta de forma más clara la intersección de elementos indígenas y coloniales se encuentra en la Cueva Matos. En esta cueva se identificó un dibujo que representa una embarcación de vela similar a las carracas o carabelas empleadas durante los viajes europeos tempranos hacia las islas (FP-3). La fecha obtenida de esta pictografía se remonta a entre cal. 1480 y 1640 d.C., relacionándose temporalmente con la presencia temprana de este tipo de embarcación en el Caribe, como se ha documentado también en otros contextos (Lace et al., 2019; López Belando, 2018). La representación pictográfica de elementos que arribaron a la isla tras su colonización se refleja además por la presencia de varias representaciones de lo que claramente son caballos en esta estación rupestre. La representación de caballos en el arte rupestre de la isla no solo se ha documentado en esta cueva, sino también en el Bo. Barahona de Morovis por Martínez Torres (1994, 2013). Resulta interesante que la imagen del barco es contemporánea con una imagen de un reptil (FP-1) aledaña, con una fecha de cal. 1440 a 1620 d.C.

Entre los elementos documentados en este periodo de interacción inicial entre los indígenas, europeos y personas afrodescendientes se destaca una imagen que ha sido identificada por visitantes previos al contexto donde apareció, en la Cueva Ventana Intermedia, como un león (FP-17). La fecha de esta imagen, la cual se remonta a cal. 1510-1650 d.C., se inserta claramente en el periodo colonial temprano de la isla. Empero, la presunción generalizada de que esta pictografía representa un león debe ser tomada con cautela porque imágenes muy similares han sido interpretadas como diseños solares en contextos precolombinos, no solo en Puerto Rico (véase FP-12), sino en Cuba (Gutiérrez Calvache et al., 2014) y la República Dominicana (López Belando, 2003, 2018). No obstante, esta pictografía tiene la particularidad de tener dos elementos que parecen representar orejas, lo que la distingue de las demás representaciones similares en otros contextos. Por tal razón, no se puede descartar la posibilidad de que en efecto esta pictografía haya sido producida por algún afrodescendiente que haya ingresado 
en esta cueva de tan difícil acceso para reflejar este tipo de animal o alguna deidad con aspecto similar (como por ejemplo, Olorum), particularmente dada la presencia de esclavos y cimarrones en esta zona desde tiempos coloniales tempranos (Delgado Colón, 1996). Cabe destacar que una de las leyendas de Cayetano Coll y Toste que se ha asociado con este sistema cavernario cuenta que esta cueva se consideraba por algunos como una:

gruta encantada, embrujada por haber sido refugios de esclavos, huidos de los ingenios, cuyas almas en pena por haber muerto en pecado mortal, salen, cual duendes de aquelarre, la noche de San Blas, a maldecir a los dueños de la hacienda de este nombre. (Coll y Toste, 1960, p. 161, citado en Delgado Colón, 1996, p. 46)

La producción de pictografías en esta cueva luego del periodo de contacto se refleja además en la fecha obtenida para la pictografía FP-23. Esta imagen refleja lo que comúnmente se ha identificado como un "lagartijo". La fecha de esta pictografía se extiende desde 1650 a 1950 d.C. cuando se calibra a $2 \sigma$, pero tiene un rango de probabilidad a ese nivel de resolución de más de un $82 \%$ de que feche entre 1650 y 1810 d.C. Resalta, que esta fecha coincide temporalmente con dos dataciones obtenidas de Cueva Ventana Superior (UGM-5109 y UGM-17563; Rodríguez Ramos 2019), las cuales son estadísticamente casi idénticas. Esto podría indicar el continuo uso de ambas de estas cuevas hasta, al menos, esas fechas, como también había sido observado en Cueva la Tembladera, ubicada en el Bo. Barahona de Morovis (Martínez Torres, 1994, 2013). Este mismo caso se ve reflejado en una pictografía de Cueva Lucero, con fechas que también van de cal. 1640-1950 d.C., pero que tiene un 89\% de que feche entre 1640 y 1810 d.C. Esto plantea la posibilidad de que se hayan continuado plasmando imágenes asociadas a las tradiciones indígenas de la isla hasta, al menos, el siglo XVII.

Entre las pictografías muestreadas se documentaron también algunas que no presentaron evidencia de radiocarbono antiguo, por lo que su resultado las califica como "modernas". Aunque el carácter arqueológico de estas no pueda ser establecido, entendemos que no deben ser descartadas como elementos insignificantes, cuando tomamos en consideración que fueron producidas en espacios arqueológicos con técnicas análogas a las usadas en tiempos antiguos con el fin de representar elementos asociados con nuestra indigenidad. Este tipo de actividad performativa es muy distinta a la registrada en el grafiti moderno, que marca una discontinuidad con las imágenes previas, aunque no en el uso de estos espacios como contextos de registro. De hecho, logramos documentar un caso interesante de pictografías modernas en Cueva Catedral, que a primera instancia aparentaban ser una nueva manifestación rupestre realizada con trazos digitales utilizando oxisoles. Estos trazos tenían una marcada correspondencia con caras antropomorfas observadas en pictografías y petroglifos en la isla. No obstante, una muestra obtenida de una imagen hecha con este método sobre un trazo realizado con carbón reveló una fecha moderna para la marca subyacente, lo que indica claramente el hecho de que dicho tipo de imagen debió haber sido realizado en tiempos recientes.

\section{Conclusiones}

Con el presente trabajo se ha pretendido comenzar a establecer unos lineamientos cronológicos para enmarcar la temporalidad absoluta del arte rupestre pictográfico de Puerto Rico. Es evidente que la muestra obtenida es sumamente limitada cuando consideramos que solo 11 de las casi 300 cuevas y abrigos donde se ha encontrado arte rupestre en la isla (Hayward et al., 2009) fueron consideradas en el presente trabajo. Por tal razón, los planteamientos aquí realizados deben servir a manera de hipótesis, las cuales se deben tratar de falsificar con estudios posteriores.

Según los datos disponibles, las manifestaciones pictográficas en Puerto Rico se comienzan a registrar desde tiempos prearahuacos, dentro de lo que 
se ha denominado El Descubrimiento y Humanización de Puerto Rico (Período 1; Rodríguez Ramos, 2010) o la Edad Arcaica (Rouse, 1992). La evidencia pictográfica datada para ese periodo se limita a elementos geométricos, lo que concuerda con la idea planteada generalmente de que este es el primer tipo de imagen que comenzó a ser producido por los primeros pobladores de las Antillas (Figura 5). Empero, el presente trabajo amplía su marco espacial al documentarse por primera vez de manera formal en contextos tempranos de Puerto Rico. Como indicáramos previamente, es muy probable que este tipo de imagen se realizara en concomitancia con los petroglifos de caras simples y segmentadas, los cuales han sido asociados con contextos arqueológicos tempranos por su íntima proximidad espacial (Dávila Dávila, 2003; Rodríguez Ramos, 2014; Rodríguez Ramos et al., 2019).

La producción de arte rupestre pictográfico se registra nuevamente entre 200 y 400 d.C., mediante la producción de caras antropomorfas. Las identificadas en este estudio son de morfología triangular con ojos lenticulares, guardando similitud con las identificadas en adornos cerámicos de tradición Saladoide. Esto indica que grupos de esta tradición cultural pudieron haber estado produciendo arte rupestre utilizando las cuevas como espacios de registro, contrario a lo asumido tradicionalmente.

Tras un hiato cronológico de, al menos, tres siglos en el uso de las cuevas, la evidencia apunta que este tipo de espacio comienza a ser utilizado de forma marcada después del 700-800 d.C., Esto no solo se refleja en la producción de arte rupestre, sino también en el uso de las cuevas con fines mortuorios (Oliver et al., 1999). Como fue planteado por Roe (2005), estas caras iniciales tienen como elemento decorativo líneas simples proyectándose desde la parte inferior de las figuras. También pudimos observar el uso de líneas sinuosas alrededor de una cara triangular, la cual muy probablemente sea una continuidad con la tradición pictográfica Saladoide, aunque hasta el presente este ha sido un tipo de elemento rara vez documentado en el arte rupestre de la isla.
La producción de elementos tales como el "bebé en frazada", así como los llamados "soles" y otros tipos de imágenes se intensifica tras el 900 d.C., cuando comienza a articularse la reserva simbólica asociada a la "Tainidad" (Oliver, 2009; Rodríguez Ramos, 2010), la cual se caracteriza por la negociación y difusión de una serie de códigos de carácter superestructural, calendárico (sensu, López Belando, 2018), y/o científico (sensu, Pérez Reyes, 2017) que se objetifican tanto en artefactos ideotécnicos como en el arte rupestre. Para el 1100 d.C., se comienzan a registrar diseños naturalistas, en especial representaciones de peces y pájaros, así como el relleno de las imágenes con pintura. Después del 1300 d.C., se comienzan a plasmar escenas que incluyen tanto animales como combinaciones de entes antropomorfos, muchos de los cuales son calificables dentro de lo que ha sido definido como la Escuela de Borbón por López Belando (2018). Para este tiempo, también aparecen las caras en forma de corazón, los tocados con decorado y las figuras humanas a cuerpo completo con manos y pies desplegados, incluyendo tanto reptiles como seres humanos. La producción de algunas de estas imágenes continúa hasta, al menos, temprano en el siglo XVII, combinándose en algunos casos con elementos que hicieron su llegada tras la invasión europea de la isla.

Los patrones antes mencionados tienen un carácter cumulativo, lo que implica que los elementos representados en un periodo pueden continuar plasmándose en tiempos posteriores. Por ejemplo, tenemos diseños geométricos no solo en contextos asociados a los primeros pobladores, sino también en estaciones muy posteriores, como se refleja en Cueva La Pita, en donde se observó un diseño reticulado (CT-4) que fechó para 1410-1450 d.C. Por tal razón, es muy importante proceder con suma cautela al momento de asignarle temporalidades específicas a las imágenes rupestres, particularmente cuando carecemos de elementos corroborativos como dataciones absolutas o contextos arqueológicos asociados que hayan sido fechados. Además, la identificación de pictografías de muy diversos niveles de complejidad 
estilística e iconográfica en contextos contemporáneos indica, de nuevo, el carácter social y culturalmente plural existente en la isla a través del tiempo y el espacio.

Estudios futuros en torno a las manifestaciones pictográficas de Puerto Rico deben no solo evaluar la validez de los planteamientos aquí realizados, sino también profundizar en el estudio diacrónico de otros aspectos de importancia en la producción de pictografías en la isla, como lo son la composición de los pigmentos, las técnicas de ejecución y su disposición espacial. Esto nos permitirá hacer una aproximación más informada sobre la importancia de este tipo de manifestación cultural y su potencial significado para las sociedades ancestrales que habitaron nuestro archipiélago.

\section{Referencias}

Alegría, R. E. (1983).Ball Courts and Ceremonial Plaza in the West Indies. Yale University Publications in Anthropology, No. 79. Yale University Press.

Bednarik, R. B. (2000). Some problems with 'direct dating' of rock-pictures. En G. K. Ward y C. Tuniz (Eds.). Advances in Dating Australian Rock-Markings (pp. 104-109). Occasional AURA Publication 10. Australian Rock Art Research Association.

Bednarik, R. B. (1992). A new method to date petroglyphs. Archaeometry, 34(2), 279-291. https://doi.org/10.1111/j.1475-4754.1992. tb00498.x.

Benedict, J. B. (2009). A Review of Lichenometric Dating and Its Applications to Archaeology. American Antiquity, 74(1), 143-172. https:// doi.org/10.2307/25470542

Castanha, T. (2011). The Myth of Indigenous Caribbean Extinctions. Palgrave MacMillan.

Chanlatte, L. \& Narganes, Y. (2005). Cultura La Hueca. Museo de Historia, Antropología y Arte.

Dávila Dávila, O. (2003). Arqueología de la Isla de Mona. Editorial Instituto de Cultura Puertorriqueña.
Delgado Colón, J. M. (1996). Apuntes históricos sobre una finca ubicada en el Barrio Hato Viejo de Arecibo donde está localizada la "Cueva del Consejo. Anejo 4 en Estudio de Evaluación de Recursos Culturales Fase $1 \mathrm{~A}$ para el Proyecto de Desarrollo Turístico-Educativo Complejo de Cuevas "El Consejo", Sector Calichosa, Bo. Hato Viejo, Arecibo, Puerto Rico, por R. Martínez Torres. Informe disponible en el Consejo de Arqueología Terrestre, San Juan.

Dubelaar, C. N. (1986). South American and Caribbean Petroglyphs. Caribbean Series 3, Foris Publications, Koninklijk Instituut voor Taal. Volkenkunde.

Dubelaar, C. N., Hayward, M. H., \& Cinquino, M. A. (1999). Puerto Rican Rock Art: A Resource Guide. Puerto Rico State Historic Preservation Office.

Fernández, R., Morales, D., Mas, M., Jorge, A., Solís, M., Parra, E., \& Rodríguez, D. (2018). La Espiral Cave (Cuba): Guano and signs of plant substances used as paint ingredients. Journal of Archaeological Method and Theory, 25(1), 289-305. https://doi.org/10.1007/ s10816-017-9329-z.

Fernández Esquivel, P., Gutiérrez Espeleta, G. \& Carrillo Jiménez, E. (2012). Felinos en la arqueología de Costa Rica: Pasado y Presente. Fundación Museos Banco Central de Costa Rica.

Frasetto, M. (1960). A Preliminary Report on Petroglyphs in Porto Rico. American Antiquity, 25(3), 381-391.

Gutiérrez Calvache, D., González Tendero, J. B. \& Fernández Ortega, R. (2014). Arte rupestre africano en las cuevas de Cuba. La necesidad de un cambio en las herramientas metodológicas. Rupestreweb. http://www.rupestreweb. info/arterupestreafricano.html.

Gutiérrez Calvache, D. \& R. Arrazcaeta Delgado. (2006).La datación en el arte rupestre. Métodos, actualidad y expectativas para Cuba. Boletín del Gabinete de Arqueología, 9(9), 140-155. 
Hayward, M. H., Atkinson, L. G., \& Cinquino, M. A. (Eds.). (2009). Rock Art of the Caribbean. University of Alabama Press.

Hayward, M. H., Atkinson, L. G., \& Cinquino, M.A. (2013). Rock Art of the Caribbean. En W. F. Keegan, C. Hofman y R. Rodríguez Ramos. (Eds.). Oxford Handbook of Caribbean Archaeology (pp. 486-502). Oxford University Press.

Hayward, M., Schieppati, F. J., \& Cinquino, M.A. (2014). Examining the Dating of Rock Art in Puerto Rico. En B. Bérard y C. Losier. (Eds.). Archéologie Caraïbe (pp. 279-302). Taboui No. 2, Collection D' Archéologie Caraïbe. Sidestone Press.

Lace, M. J., Albury, N. A., Samson, A. V. M., Cooper, J., \& Rodríguez Ramos, R. (2019). Ship Graffiti on the Islands of the Bahamas, Turks and Caicos and Puerto Rico: A Comparative Distributional Analysis. Journal of Maritime Archaeology. https://doi.org/10.1007/ s11457-019-09228-x.

Laffoon, J., Rodríguez Ramos, R., Chanlatte Baik, L., Narganes Storde, Y., Rodríguez López, M., Davies, G. R., \& Hofman, C. L. (2014). Long-Distance Exchange in the Precolonial Circum-Caribbean: A Multi-isotope Study of Animal Tooth Pendants from Puerto Rico. Journal of Anthropological Archaeology, 35, 220-233, http://dx.doi.org/10.1016/j. jaa.2014.06.004.

López Belando, A. J. (2003). El Arte en la Penumbra. Grupo BHD, S.A., Coral Hotels and Resorts, Proempresa y Fondo Europeo de Desarrollo.

López Belando, A. J. (2018). La Memoria de las Rocas: Arte Rupestre en la República Dominicana. Serigraph SA.

Martínez Torres, R. (1994). El mural de los caballitos. Catey 1, 11-14.

Martínez Torres, R. (2008). Arte rupestre de Arecibo. Catey 3, 101-210.

Martínez Torres, R. (2013). Elyacimiento "La Tembladera" en Morovis. Primer tratado de arqueología nativa. Colectivo Muchma'hol.
Martínez Torres, R. (2021). La Región del Abacoa: Presencia Milenaria del Pueblo Jíbaro. Colectivo Muchma'hol.

Mol, A. (2014). The Connected Caribbean: A socio-material network approach to patterns of homogeneity and diversity in the pre-colonial period. Sidestone Press.

Morbán Laucer, F. (1979). ElArte Rupestre de la República Dominicana: Petroglifos en la Povincia de Azua. Fundación García Arévalo.

Oliver, J. R. (1998). El Centro Ceremonial de Caguana, Puerto Rico: Simbolismo Iconográfico, Cosmovisión y el Poderio Caciquil Taino de Boriquen. BAR International Series 727. Archaeopress.

Oliver, J. R. (2005). The Proto-Taino Monumental Cemis of Caguana: A Political-Religious "Manifesto." En P. Siegel. (Ed.). Ancient Borinquen: Archaeology and Ethnohistory of Native Puerto Rico (pp. 230-284). University of Alabama Press.

Oliver, J. R. (2009). Cacique Gods and Cemi Idols. University of Alabama Press.

Oliver, J. R., Rivera Fontán, J. A. \& Newsom, L. A. (1999). Arqueología del Barrio Caguana, Puerto Rico: Resultados preliminaries de las temporadas 1996-1997. En J. Rivera Fontán. (Ed.). Trabajos de Investigación Arqueológica en Puerto Rico: Tercer Encuentro de Investigadores (pp. 7-26). Occasional Publication of the Division of Archaeology. Instituto de Cultura Puertorriqueña.

Pestle, W. J., Curet, L. A., Rodríguez Ramos, R., \& Rodríguez López, M. (2013). What's a Cuevas? An Old Paradigm in New Archaeology. Latin American Antiquity, 24(3), 243-261.

Pérez Esteban, J. A. (2014). La huella impermanente. Dibujos de humo [Tesis, Facultad de Bellas Artes San Carlos, Universidad Politécnica de Valencia]. https://riunet.upv.es/ bitstream/handle/10251/50007/La\%20 Huella\%20Fr\%c3\%a1 gil.pdf?sequence $=1 \&$ is Allowed $=y$. 
Pérez Reyes, R. (2017). El secreto mejor perdido. Ediciones Much Ma' Ho'l.

Rivera Meléndez, J. (1996). Apuntes para el estudio de la prehistoria de Cayey [Tesis de Maestría, Centro de Estudios Avanzados de Puerto Rico y el Caribe] San Juan, Puerto Rico.

Rodríguez López, M. (2001).El jaguar domesticado: Simbolismo del perro en las culturas prehispánicas de Puerto Rico y el Caribe. Revista del Instituto de Cultura Puertorriqueña, 2(3), 88-96.

Rodríguez Ramos, R. (2010).Rethinking Puerto Rican Precolonial History. University of Alabama Press.

Rodríguez Ramos, R. (2011). The Circulation of Jade across the Caribbeanscape. En C. Hofman y A. van Duijvenbode. (Eds.). Communities in Contact. Essays in Archaeology, Ethnohistory, and Ethnography of the Amerindian Circum-Caribbean (pp. 114-136). Sidestone Press.

Rodríguez Ramos, R. (2017)La temporalidad absoluta del arte rupestre pictográfico en Puerto Rico. Informe disponible en la Oficina Estatal de Conservación Histórica, San Juan.

Rodríguez Ramos, R., \& Hoopes, J. (En imprenta). The View from the Caribbean. En C. McEwan, J. Hoopes y B. Cockrell. (Eds.), Central American and Colombian Art at Dumbarton Oaks, Dumbarton Oaks Research Library and Collection.

Rodríguez Ramos, R., J. Pagán Jiménez, Y., Narganes Storde, \& Lace M. J. (2019). Guácaras in Early Precolonial Puerto Rico: The Case of Cueva Ventana. En C. Hofman y A. Antczak. (Eds.). Dearchaizing the Archaic: Middle to Late Holocene Settlers of the insular Caribbean (pp. 201-214). Sidestone Press.

Roe, P. G. (1991). The Petroglyphs of Maisabel: A Study in Methodology. En Proceedings of the XII Congress of the International Association for Caribbean Archaeology (pp. 317-370). Martinica.
Roe, P. G. (1993). Cross-media Isomorphisms in Taíno Ceramics and Petroglyphs from Puerto Rico. En Proceedings of the 14th International Congress for Caribbean Archaeology (pp. 637-671). Barbados.

Roe, P. G. (2005). Rivers of Stone, Rivers within Stone: Rock Art in Ancient Puerto Rico. En P. Siegel. (Ed.). Ancient Borinquen: Archaeology and Ethnohistory of Native Puerto Rico (pp. 285-336). University of Alabama Press.

Roe, P. G. (2009). The Mute Stones Speak: The Past, Present and Future of Caribbean Rock Art Research. En M. H. Hayward, L. G. Atkinson y M. A. Cinquino. (Eds.). Rock Art of the Caribbean (pp. 198-239). University of Alabama Press.

Roe, P.G., \& J. Rivera Meléndez. (1995). Recent Advances in Recording, Dating and Interpreting Puerto Rican Petroglyphs. En Proceedings of the XVIth Congress of the International Association for Caribbean Archaeology (pp. 444-461). Guadalupe.

Roe, P. G., Rivera Meléndez, J., \& DeScioli, P. (1999). The Cueva de Mora (Comerío, PR) Petroglyphs and Pictographs: A Documentary Project. En Proceedings of the XVII Congress of the International Association for Caribbean Archaeology (pp. 20-59). Bahamas.

Rouse, I. (1992). The Tainos: Rise and Decline of the People who Greeted Columbus. Yale University Press.

Rowe, M. W. (2005).Dating Studies of Pictographs in North America. En L. Ludendorff. (Ed.). Discovering North American Rock Art (pp. 240-264). University of Arizona Press.

Rowe, M. W. (2009).Radiocarbon Dating of Ancient Rock Paintings. Analytical Chemistry, 81, 1728-1735.

Ruiz, J. F., \& M. W. Rowe. (2014). Dating Methods (Absolute and Relative) in Archaeology of Art. Springer. 
Samson, A.V.M., Wrapson, Cartwright, L. J., Sahy, C. R., Stacey, D., \& Cooper, R. J. (2017). Artists before Columbus: A multi-method characterization of the materials and practices of Caribbean cave art. Journal of Archaeological Science, 88, 24-36. https://doi.org/10.1016/j. jas.2017.09.012.

Samson, A. V. M, Cooper, J., \& Caamaño-Dones, J. (2016). European visitors in Native spaces: Using palaeography to investigate religious dynamics in the New World. Latin American Antiquity, 27(4), 443-461.
Stuiver, M., Reimer, P.J., \& Reimer, R.W. (2021). CALIB 8.2. http://calib.org

Veloz Maggiolo, M. (1970). Informe Sobre Una Posible Metodología para la Interpretación y Posible Identificación de las Pinturas Rupestres Antillanas. Revista Española de Antropología Americana, 5, 317. 